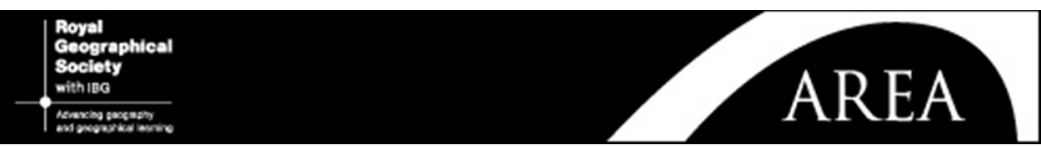

\title{
Finding the coast: environmental governance and the characterisation of land and sea
}

\begin{tabular}{|r|l|}
\hline Journal: & Area \\
\hline Manuscript ID & AREA-SI-Sep-2016-0107.R2 \\
\hline Manuscript Type: & Special Section \\
\hline Keywords: & Coast, Landscape, Seascape, Liminal, Characterisation \\
\hline & $\begin{array}{l}\text { In environmental governance for land and sea, the cultural is increasingly } \\
\text { imbricated with the natural in the language of ecosystem services and the } \\
\text { promise of integrated management. We are witnessing accelerated efforts } \\
\text { to bring cultural and natural landscape character assessments into dialogue } \\
\text { with other sorts of planning and governance mechanisms for coastal and } \\
\text { marine environments. As land, sea, nature, and culture are brought into } \\
\text { closer correspondence, the coast assumes ever greater significance as a } \\
\text { site and object of decision making in planning and environmental } \\
\text { governance. In this paper, I draw on the critical analytical techniques of } \\
\text { cultural geography to argue that coasts suffer from definitional ambiguity } \\
\text { and conceptual insufficiency, both of which are exemplified by landscape } \\
\text { and seascape characterization, with specific consequences for } \\
\text { environmental governance. I argue that we need to (i) both recognize and } \\
\text { destabilise the unhelpful dichotomy between land and sea embodied in } \\
\text { landscape and seascape character assessments, which have their } \\
\text { provenance in landscape architecture; and (ii) engage new language and } \\
\text { conceptual tools that help us to rethink coasts critically. To this end, later } \\
\text { on this paper, I briefly discuss alternative ways of conceptualising the } \\
\text { coast, for example as a liminal space. }\end{array}$ \\
\hline
\end{tabular}


Finding the coast: environmental governance and the characterisation of land and sea.

Introduction

In environmental governance for land and sea, the cultural is increasingly imbricated with the natural in the language of ecosystem services and the promise of integrated management. There are accelerated efforts to bring cultural and natural landscape character assessments into dialogue with other planning and governance mechanisms for coastal and marine environments through funding mechanisms such as Horizon 2020, for example (European Commission 2016). The European Landscape Convention (ELC) (2000) drove the evolution of Landscape Character Assessment in England ${ }^{1}$ in its current form. Landscape Character Assessment seeks to establish: "a robust, auditable and transparent, baseline" for understanding landscapes, and assisting "in informing judgements and decisions concerning the management of change" (Tudor 2014, 8). The propagation of landscape character assessment into seascape character assessment has been accelerated by the rise of ecosystem services frameworks for managing nature and the environment (Leyshon 2014) and, for the coast especially, the application of the philosophy of Integrated Coastal Zone Management and the practicalities of Marine Spatial Planning. At the heart of this acceleration lies a discourse of change (Geoghegan and Leyshon, 2014), pressure on natural and cultural landscape resources from - inter alia-climate change, population growth, urbanization, habitat fragmentation, loss of biodiversity, imperatives of economic growth, and the need to manage in an integrated way (Lloyd et al 2013).

\footnotetext{
${ }^{1}$ This paper is concerned with methods of landscape and seascape character assessment practiced in England by Natural England and Historic England (non-departmental bodies responsible for advising the government on natural and historic environments respectively). Similar methods are practiced in the UK under devolved governments in Scotland and Wales and in the EU.
} 
This paper asks how, why, and with what effects ideas about the coast are fashioned and mobilized. As land, sea, nature, and culture are brought into closer correspondence, the coast assumes ever greater significance as a site and object of decision making in planning and environmental governance (Jorgensen 2014). Much of the coast's significance revolves around the way it is conceptualized variously as an edge, a margin, a boundary, or an interface - none of which are synonymous and all of which imply a different suite of possibilities for this space and its management. The coast is also presented as a meeting point of biophysical systems between salt water and freshwater ecosystems, and between wet and dry, produced by marine and terrestrial hydrological and geomorphological processes but not entirely marine or terrestrial itself. I argue that coasts suffer from the conjoined effects of definitional ambiguity and conceptual insufficiency, exemplified by landscape and seascape characterization, with specific consequences for environmental governance.

Despite the common use of a singular noun - the coast - and a set of shared imaginaries that conjure up the seaside, coasts exhibit huge diversities. They have the potential to localize our understanding and response to environmental change through greater attention to their particular configurations of knowledges, embodied practices, senses of place and local structures of feeling. I argue that in order to do this we need to (i) both recognize and destabilise the unhelpful dichotomy between land and sea embodied in landscape and seascape character assessments; and (ii) engage new language and conceptual tools that help us to rethink coasts critically (discussed later in this paper). I begin by exploring the multiple, conflicting, ambiguous ways in which the coast is invoked, to illustrate the consequences of definitional ambiguity combined with conceptual insufficiency. 
Definitional Ambiguity

In this section, I use the interpretative approaches of cultural geography to explore the making of meaning and construction of knowledge around coasts, inspired by work on the importance of narratives in environmental governance (Köpsel et al 2016), and cultural geographers such as Castree $(2005 ; 2014)$ who cautions us to be wary of a simple natureculture binary and encourages the view that nature can be made sense of without presuming its naturalness.

In the midst of increasing quantities of strategic thinking about the land and sea, the coast occupies a dichotomous position of being both in plain sight and taken for granted. Though often cited as a site of terrestrial and marine planning, the concept of the coast lacks definitional and conceptual clarity. This neglect is evident when one compares the decades of conceptual effort invested in understanding another potentially unstable spatial category: the rural (Hoggart, 1990; Woods 2011). As with the rural, what the coast represents is far from self-evident despite the apparently straightforward meanings of 'where land meets sea'. For example, the UK government's Shoreline Management Plan ${ }^{2}$ guidance prepared by DEFRA (2011) does not include a definition of either shoreline or coast in its glossary. The organizing spatial concept for the original shoreline management plans were 'sediment cells': "the coastline and its associated nearshore area within which the movement of coarse sediment (sand and shingle) is largely self-contained" (DEFRA 2011 42). In the UK, neither DEFRA or the Joint Nature Conservation Committee provide a definition

\footnotetext{
${ }^{2}$ A large-scale report, assessing the risks associated with coastal processes. (https://www.gov.uk/government/publications/shoreline-management-plans-guidance).
} 
of the coast despite identifying its various habitats and physiographic features with forensic precision (JNCC, undated A and B). Even primarily terrestrial habitats are intertidal, freshwater or in various states of wetness at different times. Physiographic features include water bodies (e.g. sounds and lagoons) and dry land (barrier beach) or dry land now submerged such as rias or drowned river valleys (JNCC A). The coast is, by this reckoning, a specific assemblage comprised of its many habitats and physiography in which the tidy rationalities of land and water are disrupted.

Natural England ${ }^{3}$ (NE) are similarly evasive. An initiative for Heritage Coasts compounds the ambiguous standing of coasts by seeking to conserve, protect, and enhance the natural beauty of the coastline; its terrestrial, coastal and marine flora and fauna; and heritage features (Natural England, 2016). Semantically, the flora and fauna of the coast must be either terrestrial and/or marine. Less pedantically, this tripartite division does start to signal that there is something different and special about coasts.

Shoreline Management Plans, DEFRA and JNCC typologies, and Natural England Heritage Coasts are a few examples where the coast is simultaneously brought into view and left undefined: in planning guidance, evaluation, and governance documents, coasts are what coasts do. The word 'coastline' (sometimes used synonymously with 'shoreline' and coast) seems to suggest something visually unambiguous, conveniently delineating land from sea. Similarly, coastal zone is used somewhat ambiguously.

Yet coasts are more than a convenient shorthand, geomorphological or otherwise. In the UK, no-one lives more than 70 miles from the sea and the sense of being an island nation

\footnotetext{
${ }^{3}$ Natural England is the non-departmental public body which acts as the UK government's adviser for the natural environment in England, helping to protect England's nature and landscapes for people to enjoy and for the services they provide (https://www.gov.uk/government/organisations/natural-england accessed April 2016).
} 
features powerfully in the national imaginary (Geoghegan and Leyshon 2014; Matless 2016). Coasts form the (imperfect) boundaries of our terrestrial worlds, symbolizing both the limits for humans of space habitable without life support and the freedom of travel beyond our shores. Gillis (2014) traces the emergence of coast as a noun to the geopolitical project of affirming territory. Indeed, the coast as a boundary or a threshold is emphasised in different mapping conventions; the marine, the terrestrial, even the geological. The concepts of margin, boundary, and threshold have powerful symbolic resonance and, as shown below, material consequences for landscape and seascape character assessments.

The symbolic power of coasts rests in their narrative power as a beginning and an end. But what is also important is the sense of being betwixt and between, neither this nor that - a "terraqueous" place (Gillis 2014, 156) the mobility and motility of which we have been trying to still for decades. Our relationship with the sea is thus often characterized as a triumph of human ingenuity in reclaiming land, stabilizing shores, dredging harbours, making new islands, 'holding back' the destructive force of storms, surges, waves, and tides, attempting to materially, literally, and figuratively stabilize the fluid boundary. When these efforts are eventually thwarted by the sea we feel afresh our vulnerability to natural forces. Efforts to maintain the coast as a physical and symbolic boundary are increasingly challenged by the contemporary realities of environmental change, offshore and onshore developments (e.g. renewables), economic development, and resource extraction, among others. I discuss briefly one example here: climate change, manifested through sea level rise and more frequent and violent of storm events. In the UK, for example, where the majority of the population recognise climate change (Defra, 2009) but have not been moved to act (Lorenzoni et al., 2007), coasts are a site of visible, tangible, and intangible change (Lloyd et al 2013). Geoghegan and Leyshon (2014) show how the National Trust for England and 
Wales have adopted "Shifting Shores" as a tagline for their approach to adaptive management, deploying a variety of narrative and discursive strategies to call attention to the conjoined threats of erosion and flooding to National Trust properties near the sea (Geoghegan and Leyshon, 2014). Climate change is powerfully materialized in the managed realignment policies for iconic sites, e,g. the inconic harbor at Mullion Cove in Cornwall, UK (DeSilvey 2012).

Vulnerability is not only about the sea washing over the land. Terrestrial life forms, habitats, ecosystems and cultural heritage of all kinds sometimes butt up against the physical boundary between land and sea in ways which call attention to how diminished they have become and how squeezed from the landward side by intensive agriculture or settlement (Shipman and Stojanovic, 2007).

How, then, can we come to know the coast in all its symbolic, material, biophysical, cultural complexity and foreground its potential and significance in environmental governance? In the next section, I destabilise the unhelpful dichotomy between land and sea embodied in landscape and seascape character assessment in the UK. These are the primary instruments of assessment for natural and cultural heritage in planning processes for terrestrial and marine spaces by which the coast will be known to planners and environmental managers. Yet, despite the symbolic potency of the coast, these mechanisms do little to help us understand the particular relational qualities of coasts - which is to say, part of an "openended, mobile, networked, and actor-centred geographic becoming" (Jones, 2009, 487). 
In the UK, landscape and seascape character assessments follow methods and guidelines set down by NE and Historic England (HE). ${ }^{4}$ Some form of landscape evaluation has been practiced in the UK since the 1970s (Swanwick, 2002). Since 1993 landscape character has been the dominant concept underpinning landscape assessment, incorporating the "rich heritage of landscape diversity" into planning and decision making (Tudor 2014, 7). Historic Landscape Character assessments were adapted by English Heritage (now Historic England) from Landscape Character Assessments to amplify the historic perspective in these assessments (Fairclough and Macinnes 2003; Tudor 2014).

Within the UK, the Marine and Coastal Access Act 2009 set the trajectory for the strategic and integrated management of the seas. The subsequent UK Marine Policy Statement (MPS) (HM Government 2011) promised both clarity and consistency in the management and use of UK waters and set out the framework for producing Marine Plans. Together, the MPS and Marine Plans form a new plan-led system for marine activities that are intended to sit alongside and interact with existing planning regimes in the UK, integrating marine and terrestrial planning with consistent policy documents and guidance (HM Government 2011). MPS and Marine Plans should be compatible with the principles of Integrated Coastal Zone Management (HM Government 2011). Shipman and Stojanovic $(2007,389)$ argue that the focus on the marine zone as an entity threatens a policy-driven coastal squeeze wherein terrestrial administrations and spatial plans are "rigidly limited to the tide line". Nevertheless, Shipman and Stojanovic's assert that "the line between land and sea seems as rigid as ever" $(2007,389)$. With this in mind, the following paragraphs set out several ways

\footnotetext{
${ }^{4}$ Historic England is the government's statutory adviser on the historic environment, championing historic places and helping people to understand, value and care for them. HE is an executive non-departmental public body (https://www.gov.uk/government/organisations/historic-england accessed 5 April 2016).
} 
in which coasts remain an unexamined discourse in landscape and seascape character assessments. Separately and in combination, these serve to maintain an unhelpful dichotomy between land and sea which also sets the conceptual tone for environmental governance and management. The conceptual limits around land and sea underplay the material and symbolic importance of coasts, their relational and processual qualities, and the complexity of human and natural processes that operate over multiple timescales.

NE guidance on Landscape Character Assessment states that:

\author{
Landscape character may be defined as a distinct, recognizable pattern of \\ elements, or characteristics, in the landscape that make one landscape different \\ from another, rather than better or worse. Landscape Character Assessment \\ (LCA) is the process of identifying and describing variation in the character of the \\ landscape. It seeks to identify and explain the unique combination of elements \\ and features (characteristics) that make landscapes distinctive. This process \\ results in a production of a Landscape Character Assessment (Tudor, 2014, 8 \\ emphasis in the original).
}

\begin{abstract}
LCA is thus based on a familiar epistemology that emphasizes the materiality of landscape and its qualities as a mosaic of natural and cultural features and influences (though see below for recent developments). With its provenance in the ELC and the post-war planning system in England, LCA exerts epistemic dominance over both landscape and seascape character assessments that lie downstream of it. The Countryside Agency and English
\end{abstract}


Heritage $^{5}$ described the relationship between Historic Landscape Characterization and LCA as "close", pointing out that "the methods used in HLC/HLA 6 are partly derived from those used in Landscape Character Assessment, which facilitates incorporating the results of HLC/HLA into Landscape Character Assessment" (Fairclough and Macinnes 2003 p.1).

Landscape Character Assessment and Historic Landscape Characterization are both, not surprisingly, determinedly terrestrial. The coast is not a character type in its own right and there are two opposing ways of reading this. On the one hand, promoting the coast as a single character type is counterintuitive given the diversity of coastal environments. On the other hand, the coast seems to be relegated to something that gives flavor to an otherwise profoundly land-based typology. Small villages are 'coastal' which suggests more about their location than something specific in their character. In Cornwall ${ }^{7}$, where Historic Landscape Characterization was designed and piloted in 1994 (Cornwall Council 2016), the sea surrounds the narrow peninsula on three sides and is only $20 \mathrm{~km}$ away at east Cornwall's widest point. Yet the original HLC zones include only one category - Coastal Rough Ground that hints at anything different about the character of the land nearest the sea.

\section{Guidance on Seascape Character Assessments and Historic Seascape Characterization are} also provided by NE and HE respectively. As mentioned, seascape character assessments drew heavily on their landscape counterparts in their design and application, as the foundational guidance document, NECR105 An Approach to Seascape Character Assessment (Natural England 2012 11.) shows:

\footnotetext{
${ }^{5}$ The Countryside Agency was a statutory body set up in 1999 in England to improve the quality of the rural environment. Some of its activities were merged with English Nature and parts of the Rural Development Service to form Natural England in 2006. English Heritage was reorganised in 2015 with some of its functions transferred to the voluntary sector and some to Historic England.

${ }^{6}$ Historic Landscape Characterization (HLC) is my concern here. Historic Landscape Assessment (HLA) is the Scottish variant.

${ }^{7}$ Cornwall was historically a county but now a unitary authority.
} 
The process of Seascape Character Assessment follows the well-established and widely used principles and stages set out in Landscape Character Assessment guidance, with emphasis given to particular issues that need to be considered when assessing coastal and marine environments.

Seascape is a term fraught with ambiguity. It is variously described by NE and the UK Government in the following ways (emphasis added):

\begin{abstract}
NE: Seascapes: "an area of sea, coastline, and land, as perceived by people, whose character results from the actions and interactions of land with sea, by natural and/or human factors" (Natural England 2012a, 8).
\end{abstract}

\begin{abstract}
UK Gov: "In the context of this document [UK Marine Policy Statement] references to seascape should be taken as meaning landscapes with views of the coast or seas, and coasts and the adjacent marine environment with cultural, historical and archaeological links with each other" (HM Government 2011).
\end{abstract}

\begin{abstract}
Meanwhile, HE aver any definition and refer only to what Historic Seascape Characterisation seeks to achieve: mapping and describing "those historic cultural influences that shape present seascape perceptions across all of England's marine areas and coastal land" (Historic England 2016 unpaginated). Their concern extends to "land settled by people after the last Ice Age but now submerged"; historic activities such as naval battles, maritime trading, and fishing; and "coastal land which possesses
\end{abstract}


a distinctly maritime character" (Historic England 2016 unpaginated). Questions of perception are treated lightly, with the emphasis on geographical coverage.

From the academic literature comes a set of definitions with a different emphasis again (emphasis in original):

Landscape is the visible interaction of abiotic, biotic and human processes developing on the earth surface over time. The interaction of these processes on the coast, sea and adjacent waters constitutes the seascape (Pungetti 2012, 52).

Pungetti goes on to describe the multiple definitions of seascape which encompass space, place, visual components, and biophysical processes, ending with a final analysis in which 'coastline' again appears as a third space:

The concept of seascape, initially meaning a picture or view to the sea, or a view of an expanse of sea (Oxford English Dictionary), has been broadened to mean the coastal landscape and adjoining areas of open water, including views from land to sea, from sea to land and along the coastline (Hill et al., 2001). As it can describe the effect on landscape at the confluence of sea and land, seascape becomes an area of intervisibility between land and sea, with three defined components: sea, coastline and land (DTI, 2005) (Pungetti, 2012, 52).

Along with this definitional tangle, in which the imbrications of land and sea are struggled with, come statements about the proper use of landscape and seascape characterisations which do little to abrogate the ambiguous status of the coast in relation to land and sea. 
NE's guidance on Seascape Character Assessment from 2012 provides an instructive dialogue box on its proper use in which it is suggested that Seascape Character Assessment should be applied principally to "coastal and marine areas seaward of the low water mark" whilst Landscape Character Assessment "principally applies to areas lying to the landward side of the high water mark" (Natural England 2012a, 7). Intertidal areas (between the high water mark and the low water mark) can be assessed using either Landscape Character Assessment or Seascape Character Assessment approaches.

The coast is thus where both landscape and seascape character assessments become interchangeable. This is possible because the coast is so indeterminate that it can be treated as land or sea and because there is very little if any ontological or epistemic distance between landscape and seascape character assessment. Tudor (2014, 13 emphasis added) endorses this as a strength of characterization, arguing that "approaches to Landscape Character Assessment and Seascape Character Assessment suggest a seamless approach to the character assessment of land and sea. Both follow a common approach, but each is tailored to the particular environment being assessed". It is as if seascapes are the same as landscapes, only wetter. ${ }^{8}$ Gillis (2012, 159, original emphasis) describes this as "a tendency for land to incorporate the sea, to treat it like itself, as territory that can be parceled, leased and owned. In effect, the sea has become continentalized".

This continentalisation or, as I prefer to think of it, the terrestrialisation of the sea is made visually apparent in the attractive diagrams (figure one) used to describe "what is landscape" and "what is seascape" in guidance documents (Swanwick 2002; Natural England

\footnotetext{
${ }^{8}$ The lessons learned from the pilots of Seascape Characterisation around the English coast note that, whilst the guidance provided was comparable to that of landscape character assessments, "an understanding of the influence of the below water environment is fundamental to interpretation of the character of an area" (Natural England 2012c, 8).
} 
2012a). In fact, these diagrams represent considerable progress in recognizing the imbrications of culture and nature, and the affective qualities of an encounter with land and sea, though the guidance from NE provides few methodological pointers about how an affective relationship should be captured in the desk-based or field survey phases of seascape character assessment. Guidance on the desk-based phase suggests that the media, people, events, legends/folklore, musicians, writers, and artists are a source of information about cultural associations. The field survey is in part intended to "inform written descriptions, notably to capture aesthetic, perceptual and experiential qualities" by "recording aesthetic and perceptual experiential aspects in the field" (Natural England 2012a, 23) including sight (colour, texture, pattern, form), sounds, smells, touch/feel, memories, preferences, and cultural associations. There is no guidance on the appropriate qualitative methods to evaluate, for example, smell, touch and memory (Natural England 2012c). Nevertheless, as a think piece it is useful to imagine what this diagram would look like for the coast. How would coasts be differently imagined - as porous and connective, fractal, with a unique history and geography (Pearson 2005) - if they were not relegated to an unstable category of near-sea land or near-land sea?

\section{FIGURE ONE HERE}

Paradoxically, the terrestrialisation of seascape character assessment does not mitigate the separation of land and sea into mutually exclusive categories, to the detriment of our understanding of the coast. It is in the gaps and ambiguities in the definitions of seascape and landscape that we glimpse both the particular qualities of the coast and the challenges facing it. How, for example, can coasts be actively and productively included in the various 
vehicles of integrated coastal zone management if they are in continuous tension between landscape and seascape and the means by which these are characterized? The accepted dualism of land and sea treats coasts like a thin layer of meat of uncertain origin in a cheap sandwich.

A conceptual space for the coast

Seascape and landscape characterization imply that cultural geographies of the coast will be taken seriously, combining as they do elements of performative, affective, embodied, and material associations with place. But if this is to be achieved, two linked intellectual challenges must be met. First, the imperative to consider assorted cultural associations some of which are intangible and ephemeral - must be matched by appropriate methods of data collection and analysis which embrace post-positivist approaches. Cultural geography brings a richly theorized concern for both questions of representation and nonrepresentational approaches which would help in the understanding of our multisensual encounter with place and the way we choose to represent those places to ourselves and to the world in different ways (see, for example, Lorimer 2005). Cultural geographers also bring decades of working on innovative qualitative and participatory methods designed to capture the intangible, multisensory, affective qualities of place (see for example Dewsbury 2010; Thrift 2007). Second, a new conceptual space for the coast must be created which goes beyond Euclidian thinking. As well as finding "a narrative that is less terracentric, one that recognizes humanity's long relationship with the sea as an edge species" (Gillis 2012, 9), we also need to realise and act upon coasts as always in the process of becoming through heterogeneous interrelations at multiple spatial and temporal scales. 
Gillis (2014) brings some conceptual heft to understanding coasts through his use of 'ecotones' - a place where two ecosystems connect and create a unique environment different from both - which he originally used to challenge conventional assumptions about small islands as bounded territorial units. In a different vein but still with the intent to conceptualise the coast, Pearson attempts to ascribe unique qualities to 'littoral society', which occupies what Steinberg $(2001,138)$ called the "land-like territorial waters" or coastal sea zone, the beach and "some indeterminate frontier on land" (Pearson 2006, 354).

A further concept that calls attention to the special characteristics of the coast is liminality. As spaces of transformation at many spatial and temporal scales, coasts are relational, fungible, material, symbolic, and processural. They are defined by a dynamic that is at a minimum the diurnal movement of water and all that it carries towards the shore, whether in an insidious creeping tide or a storm-driven swell. To characterize coasts as liminal in space and time is to draw attention to their ambiguity, openness and indeterminacy and to invite fresh thinking about future change in these highly motile spaces.

Liminiality is a concept that has traveled a long way since the cultural anthropologist Victor Turner "tossed speculatively into the pool" of his anthropological data "like a pebble to understand ritual and rites of passage" (Turner 1977, 36). These had three episodes: separation, margin (or limen), and re-aggregation in which a ritual subject is detached from their old place in society and returned transformed to a new place (Turner 1977). While transformation is the main concern of anthropologists, the idea of liminality has leaked out into geography and other disciplines to describe - variously - spaces on the margins, spaces in which social conventions and expectations are suspended, where the range of possibilities is expanded, where transformation happens (see for pertinently Preston-Whyte 
2004). Liminality is useful in two main ways. First, as a heuristic, thinking about coasts as liminal spaces may help us to characterise more critically the important symbolic status of coasts as ever-changing conjoined cultural and natural landscapes in time and space.

Thinking of coasts as liminal spaces prevents them suffering the conceptual insufficiency that results from organizing our thinking only around land and sea and helps to direct attention to them. Second, liminality could be a tool to challenge conventional modes of thinking about the current management for future change by emphasizing transformation as an inherent characteristic and basic starting point. Hence, in liminal spaces, there is an expectation that conventional modes of thinking and conventional framings of the coast will be destabilized.

Working with liminality helps us to characterize coastal change itself as part of a rite of passage, a transformation for humanity into an altered future state, but one which is indeterminate. Using the concept of anticipatory history, DeSilvey (2012) has shown how constant change is a feature of not only the geomorphological but also social history of Mullion, a harbor on the Lizard Peninsula. Leyshon and Geoghegan (2012) have used anticipatory objects and the concept of uncertain imminence to provide some correspondence between the statistical phenomena that is climate change, the timescales over which it is discussed, and how all this is imbricated into local landscapes, practices and identities. Nevertheless, we continue to exhibit a sort of path dependence on stable future outcomes from our management stratagems. Liminality offers the potential for alternative constructions of landscape, seascape, and coast both temporally and spatially. Liminal space feels uncomfortable - the conceptual ground is shifting under our feet as much as the real ground - but in as much as liminality offers ambiguity and transition it also presages arrival at a stable, if transformed future state. 
Conclusion

In this paper I am not arguing for greater definitional clarity for coasts. In fact, if decades of work in rural geography on what is 'rural' are anything to go by, repeated attempts at definitional clarity does not of necessity generate greater conceptual clarity. Rather, the conceptual endeavors around the rural have allowed it to emerge as a complex, nuanced space - an assemblage rather than a stable or essentilised material-semiotic category. Landscape and seascape characterizations are functionaries in a system of environmental governance that tends to elide the particularities of coast, subsuming them into a categorization as land or sea in a way that avers both the unique mingling of the two and the particular dynamics of people, objects, knowledges, processes, problems, and negotiations. We need a new language to think and relate to the coast, and liminality is aligned with change, transformation, possibility - in space, time, and practice. Liminality as a concept insists that we see and accept coasts as places of transition, and ourselves within them.

Reference list

Castree N 2005 Nature Routledge London and New York

Castree N 2014 Making Sense of Nature Routledge London and New York 
Cornwall Council 2016 Historic Landscape Character

https://www.cornwall.gov.uk/environment-and-planning/historic-environment/cornwall-

and-scilly-historic-environment-record/historic-landscape-character/ (accessed 1 June 2016)

Council of Europe 2016 European Landscape Convention www.coe.int/de/web/landscape

(accessed 5 April 2016)

Defra 2009 Public attitudes and behaviours towards the environment-tracker survey.

http://webarchive.nationalarchives.gov.uk/20130822084033/http://www.defra.gov.uk/evid

ence/statistics/environment/pubatt/download/report-attitudes-behaviours2009.pdf

(accessed 1 June 2016)

Defra 2011 Shoreline management plan guidance volume 1: aims and requirements

Ref: PB11726. https://www.gov.uk/government/publications/shoreline-management-plansguidance (accessed June 2016)

DeSilvey C 2012 Making sense of transience: an anticipatory history Cultural Geographies 19 $31-54$

Dewsbury JD 2010 Performative, non-representational, and affect-based research: seven injunctions in DeLyser D ed The Sage Handbook of Qualitative Geography Sage Publications 321-334 
European Commission 2016 Cultural heritage of European coastal and maritime regions https://ec.europa.eu/research/participants/portal/desktop/en/opportunities/h2020/topics/ cult-coop-07-2017.html (accessed 6 March 2017)

Fairclough G and Macinnes L 2003 Landscape Character Assessment Guidance for England and Scotland. Topic Paper 5: Understanding Historic Landscape Character The Countryside Agency and Scottish Natural Heritage http://publications.naturalengland.org.uk/file/6029271747264512 (accessed 5 April 2016) Geoghegan H and Leyshon C 2014 Shifting shores: managing challenge and change on the Lizard Peninsula, Cornwall, UK Landscape Research 39 631-646

Gillis J R 2012 The Human Shore The University of Chicago Press Chicago and London Gillis J R 2014 Not continents in miniature: islands as ecotones Island Studies Journal 9 155166

Historic England 2016 Characterising Historic Seascape.

https://www.historicengland.org.uk/research/approaches/researchmethods/characterisation-2/historic-seascapes/ (accessed 1 June 2016) HM Government 2011 UK Marine Policy Statement HM Government Northern Ireland Executive Scottish Government Welsh Assembly Government The Stationery Office London 
Hoggart K 1990 Let's do away with the rural Journal of Rural Studies 6 245- 257

JNCC undated A Coastal Physiographic Features. http://incc.defra.gov.uk/page-5589 (accessed 1 June 2016)

JNCC undated B UK Coastal Habitats. http://jncc.defra.gov.uk/page-1429 (accessed 1 June 2016)

Jones M 2009 Phase space: geography, relational thinking, and beyond Progress in Human Geography 33 487-506

Jorgensen A 2014 Editorial: The social dimensions of landscape change in coastal and wetland environments Landscape Research 39 609-612

Köpsel V, Walsh C, Leyshon, C. 2016 Landscape narratives in practice: implications for climate change adaptation Geographical Journal doi:10.1111/geoj.12203

Leyshon C. 2014 Cultural Ecosystem Services and the Challenge for Cultural Geography Georaphy Compass 8 701-709

Leyshon (née Brace) C and Geoghegan H 2012 Anticipatory objects and uncertain imminence: cattle grids, landscape and the presencing of climate change on the Lizard Peninsula, UK Area 44 237-244 
Lloyd MG, Peel D, Duck W 2013 Towards a social-ecological resilience framework for coastal planning Land Use Policy 30 925-933

Lorenzoni I, Nicholson-Cole S, and Whitmarsh, L 2007 Barriers perceived to engaging with climate change among the UK public and their policy implications Global Environmental Change 173 445-459

Lorimer H. 2005 Cultural geography: the busyness of being 'more-than-representational'. Progress in Human Geography 29 83-94

Matless D 2016 Landscape and Englishness $2^{\text {nd }}$ edition Reaktion London

Natural England 2012a An Approach to Seascape Character Assessment Natural England NECR105

https://www.gov.uk/government/uploads/system/uploads/attachment data/file/396177/s eascape-character-assessment.pdf (accessed 6 March 2017)

Natural England 2012b Seascape Characterisation around the English coast (Marine Plan Areas 3 and 4 and part of Area 6 pilot study) Natural England NECR106 http://publications.naturalengland.org.uk/file/2945179 (accessed 6 March 2017) Natural England 2012c Seascape Characterisation around the English coast (Marine Plan Areas 3 and 4 and part of Area 6 pilot study) Annex 2: Lessons learnt and methodological 
development Natural England NECR106

http://publications.naturalengland.org.uk/file/2913491 (accessed 6 March 2017)

Natural England 2016 Heritage coasts: definition, purpose and Natural England's role https://www.gov.uk/government/publications/heritage-coasts-protecting-undevelopedcoast/heritage-coasts-definition-purpose-and-natural-englands-role (accessed 1 June 2016)

Pearson M N 2005 The world of the Indian Ocean: 1500-1800 Aldershot Ashgate

Pearson M N 2006 Littoral Society: The Concept and the Problems Journal of World History $17353-373$

Preston-Whyte R 2004 The Beach as a Liminal Space in Lew AA, Hall CM and.Williams AM eds A Companion to Tourism Blackwell Publishing Ltd, Malden, MA, USA

Pungetti G 2012 Islands, Culture, Landscape, Seascape Journal of Marine and Island Cultures $151-54$

Shipman B and Stojanovic T 2007 Facts, Fictions, and Failures of Integrated Coastal Zone Management in Europe Coastal Management 35 375-398

Steinberg P E 2001 The Social Construction of the Ocean Cambridge University Press, New York 
1

2

3

4

5

6

7

8

9

Swanwick C 2002 Landscape character assessment guidance for England and Scotland. Topic paper 1: recent practice and the evolution of landscape character assessment The Countryside Agency and Scottish Natural Heritage. Available at http://publications.naturalengland.org.uk/file/6522413248413696 (accessed 6 March 2017)

Thrift N 2007 Non-representational Theory: Space, Politics, Affect Routledge London and New York

Tudor C 2014 An Approach to Landscape Character Assessment Natural England https://www.gov.uk/government/uploads/system/uploads/attachment_data/file/396192/I andscape-character-assessment.pdf (accessed 6 March 2017)

Turner V 1977 Variations on a Theme of Liminality in Moore S F and Myerhoff B G eds Secular Ritual Van Gorcum Ltd 36-52

Woods M 2011 Rural Key Ideas in Geography Routledge London and New York 

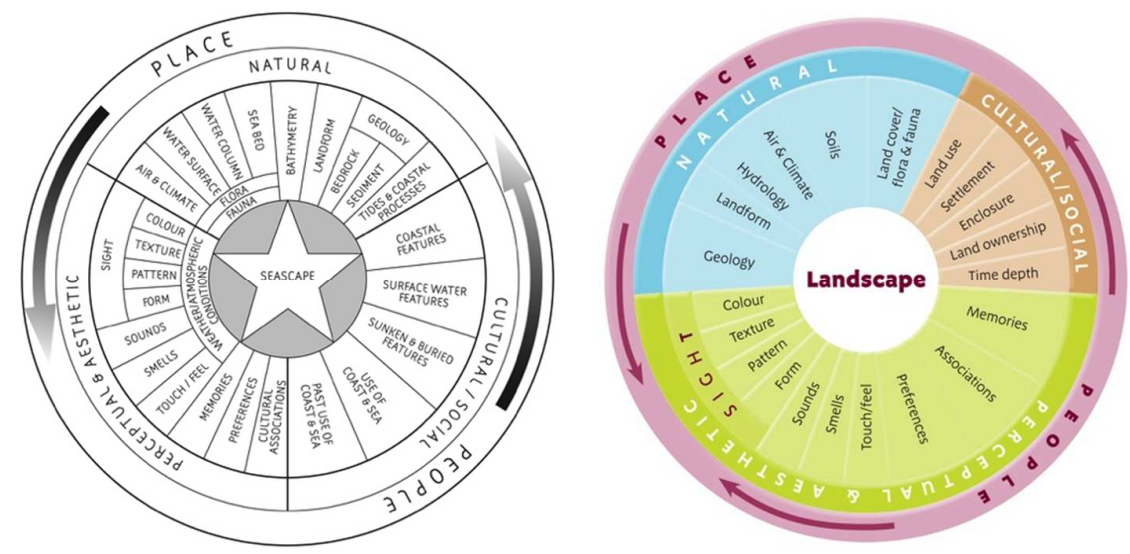